\title{
Analysis of batch asymmetry and batch line position for the decision support in the glass melting process
}

\author{
Maciej Klemiato $^{1}$ (1) $\cdot$ Paweł Rotter $^{1} \cdot$ Andrzej Skowiniak $^{2}$
}

Received: 3 February 2021 / Accepted: 29 March 2021 / Published online: 11 April 2021

(c) The Author(s) 2021

\begin{abstract}
This paper presents the results of research on the analysis of historical data from a vision system developed by the authors, installed inside a glass furnace in one of the packaging glassworks. In particular, the authors focused on analysis of the batch blanket asymmetry coefficient and the batch line position in the furnace tank. The information obtained from the vision system allows to see phenomena occurring in the glass furnace that were previously difficult to notice. Based on this, recommendations for operators have been formulated to facilitate the glass melting process more efficiently. Based on historical process data from the SCADA production system, several models were developed that allow the batch line position in the glass furnace to be estimated. The best accuracy was achieved using the model based on neural networks. Such a model can be used to optimise furnace operation, which is at present based on the experience of human operators.
\end{abstract}

Keywords Computer vision $\cdot$ Decision support $\cdot$ Furnaces $\cdot$ Glass industry $\cdot$ Industrial plants

\section{Introduction}

Glass furnaces are a crucial part of the production line in every glass factory. The operating parameters of furnaces have a decisive influence on the efficiency of the process and pollution (especially $\mathrm{NO}_{\mathrm{x}}$ emission), and on the quality of the final product. Therefore, its correct operation is extremely important. To a large extent, the parameters of the glass are estimated by the operator on the basis of the image from a camera installed inside the furnace. In particular, the operator should ensure the optimal positioning of the batch line (i.e. the distance to which the unmelted glass pieces reach) and similar distribution of the unmelted glass on both sides of the furnace. If the batch line moves too close to the working end of the furnace, the glass quality

Maciej Klemiato

mkl@agh.edu.pl

Paweł Rotter

rotter@agh.edu.pl

Andrzej Skowiniak

andrzej.skowiniak@techglass.pl

1 Faculty of Electrical Engineering, Automatics, Computer Science and Biomedical Engineering, AGH University of Science and Technology, Kraków, Poland

2 Techglass Ltd., Kraków, Poland dramatically decreases, while the batch line too close to the front of the tank results in high emissions of $\mathrm{NO}_{\mathrm{x}}$, and $\mathrm{CO}_{2}$ [1] and unnecessary energy consumption, which is a significant part of production costs [2].

The subject of the research is a glass furnace with a capacity of approx. 150 tons a day. A schematic drawing of the furnace is shown in Fig. 1. It is a $6 \times 10 \mathrm{~m}$ furnace with one hopper located on the left side. ${ }^{1}$ Two gas burners (left and right) are used to melt the glass in the furnace, working alternately for $30 \mathrm{~min}$. The process of changing the working burner (called the reversal) lasts one minute. During this time, neither of the burners are working. Every $30 \mathrm{~min}$ it is therefore possible to obtain an image of the glass pane inside the furnace, not obscured by the flame of a burner. This determines the maximum frequency at which the camera on the wall of the furnace opposite the burners can analyse the image. Two sets of electric electrodes are used to heat the glass from the bottom-one in the melting part of the furnace and the other at the break wall.

\footnotetext{
${ }^{1}$ In this article, all references to the sides of the furnace follow the camera's viewing direction. This is the opposite of industry convention, where side references are typically in the direction of gas discharge from the burners.
} 


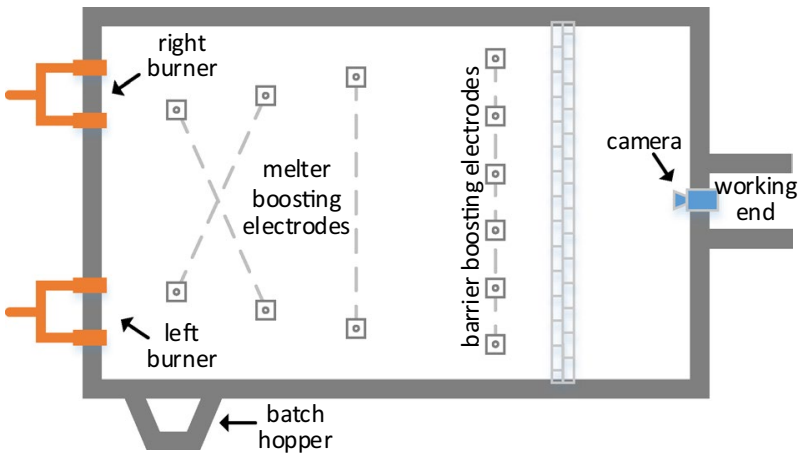

Fig. 1 Glass furnace

\section{Previous work}

Computer vision systems are becoming common elements of production lines. They are used for the inspection and control of industrial processes, including glass production. Various vision systems have been developed for monitoring different glass manufacturing stages, from the hot end of the production line, for example vision systems for gob inspection $[7,8]$ to the inspection of semi-products and the final product $[9,10]$. Vision systems have also been applied for the inspection of furnace structure [11] or vision-based analysis of flames [12].

In the literature, there is also some research on computer vision for the automatic detection of batches in glass furnaces $[13,14,19]$ the distribution of which is crucial for the correct control of the furnace. Vision systems can be used not only for full automation of the process, but also to help the operator to make correct decisions by making suggestions. They may also help by visually presenting the furnace interior, as in [15], where the image from a single furnace camera is used to create an enhanced 3D image of the furnace, which can be viewed from a virtual camera located at an arbitrary point in the furnace or using stereoscopic devices.

This study is a continuation of our previous research on the vision system supervising the operation of a glass furnace $[3,4]$ and control systems in the glass industry [5]. In the above-mentioned works, we proposed an image processing method for automatic analysis of the symmetry of the glass melting process based on a series of images captured by a camera inside a glass furnace. We recommended a set of asymmetry indicators that are not influenced by asymmetries that result from glass melting technology (i.e. consecutive heating of first one, then the other side of the furnace). As a result of this research we proposed rule-based system which makes inferences about the asymmetry of chargers and burners from the distribution of the batch on the glass surface and the distribution of correlated colour temperature. The proposed method indicates the reasons for any asymmetry, for example whether heating of the left and right hand sides of the furnace is unbalanced or whether chargers are not working properly.

The above works resulted in the SCADA-like industrial vision system for glass furnaces supervision, which is briefly described in [6]. The system was implemented in the glassworks and the results of its operation are presented in the following chapters. In particular, we focused on analysis of historical data from the period of over a month of operation of the furnace, concerning the asymmetry of the batch and the position of the batch line. Based on the data, selected statistics of furnace operation were calculated. An attempt was also made to calculate the position of the batch line using regression and neural models, based on historical process data from the SCADA system.

The main contribution of this research is thorough analysis of the furnace process variables and indicators provided by the vision system over a long time. These studies gave deeper insight into the melting process and showed that it is possible to model certain aspects of the furnace operation by the use of machine learning technics based on historical data. Analysis performed here is, according to our knowledge, the first study of this type based on real data obtained during the glass melting process.

\section{Vision system}

The research presented in this paper is based on the vision system created by the authors, whose prototype version was described in [3]. It was initially used for the extraction of relevant glass melting parameters based on pairwise comparisons [4]. The system was later developed [6], and the current version is equipped with tools for remote connection to the glassworks, making it possible to collect and process data remotely in real time. It also includes tools for statistical analysis of data, such as statistics describing the variability of the distribution of the batch over time, including symmetry analysis. The interface of the system is presented in Fig. 2.

Our vision system calculates the distribution of the batch at each reversal, based on an image from a camera placed in the furnace. Then, on the basis of the distribution, the average asymmetry value of the batch is calculated based on the following procedure: 


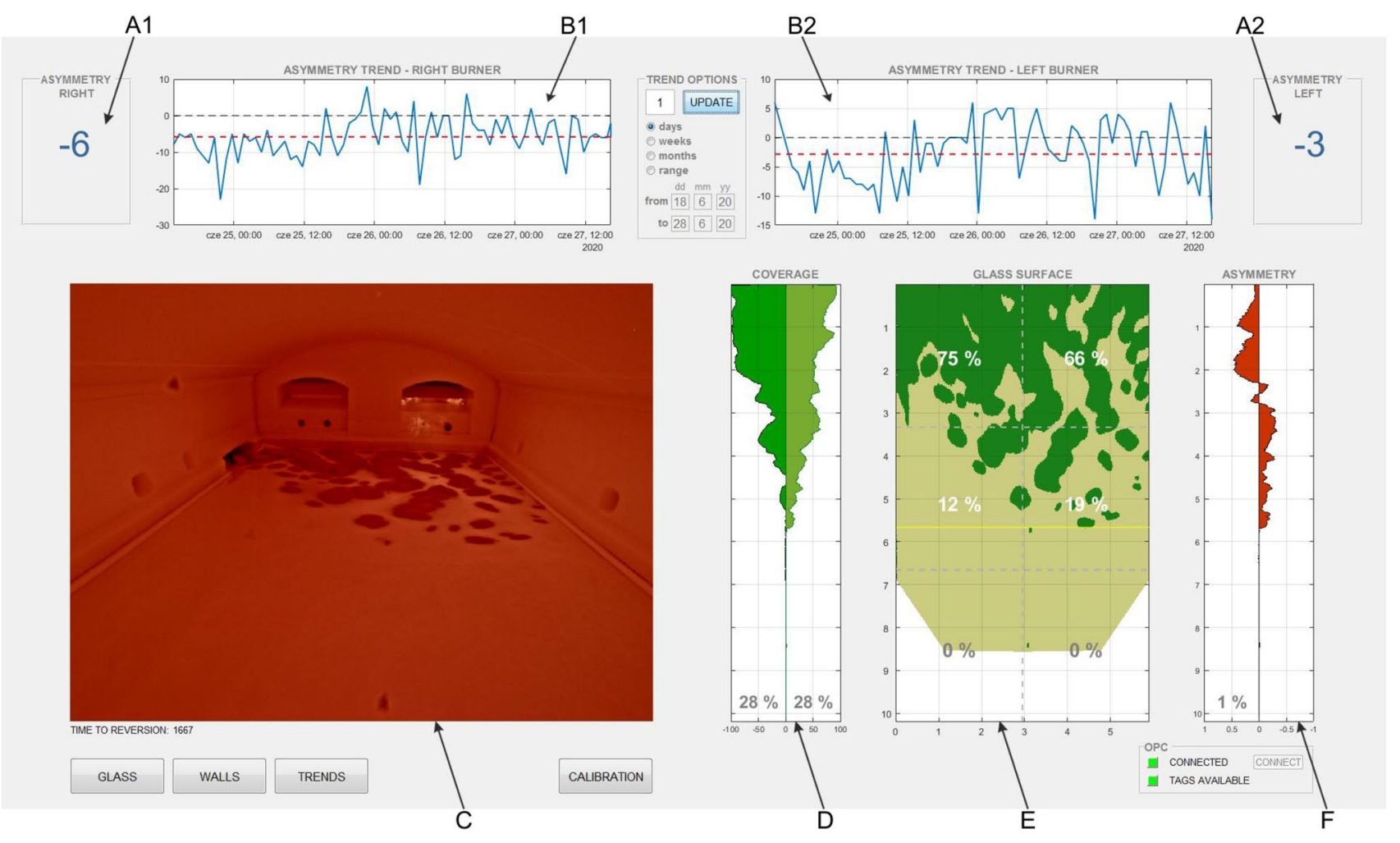

Fig. 2 Main window of the vision system. Depictions: a1 and a2, mean values of asymmetry coefficients for defined period of time for right and left burner; b1 and b2, asymmetry trends for right and left burner; c, an image of the furnace from the camera; $\mathbf{d}$, the batch cov-

1. Segmentation ${ }^{2}$ of the batch from the camera imageFig. 2c (i.e. making a distinction between the raw material and the melted glass [3]).

2. Geometric transformation to the view from above [16] Fig. 2e.

3. Calculation of the batch coverage of the right side and of the left side of the furnace as a function of $x$ coordinate, i.e. the percentage of batch coverage for each line perpendicular to the furnace axis $X$. The result of this operation is shown in Fig. 2d.

4. Calculation of the difference between the right and left coverage as a function of $x$ coordinate. The result of this operation is shown in Fig. $2 \mathrm{f}$ (the vertical line is the centre of the furnace; if the graph is on the left side of this line, it means that there is an asymmetry with more batch on the left side of the furnace).

5. Calculation of the mean value from the diagram in Fig. $2 \mathrm{f}$. This value is the mean asymmetry of the batch

\footnotetext{
${ }^{2}$ In glass melting technology the term segmentation may also refer to the separation of the stages of the glass fusion process into distinct devices [17]. However, in this article we use 'segmentation' in the context of image analysis, where it means automatic separation of different image areas.
}

erage of the right and left sides of the furnace; e, batch blanket after geometric projection; $\mathbf{f}$, distribution of the batch asymmetry for actual reversal

for a given reversal, which is plotted as a time series in Fig. $2 b 1$ (for the right burner) and Fig. $2 b 2$ (for the left burner).

Since the nature of the asymmetry differs significantly depending on which burner preceded the given reversal (which will be further elaborated in the next chapter), the trend is drawn separately for the left burner (more precisely - for the series of every second reversal preceded by operation of the left burner) and for the right burner.

Additionally, on the basis of the batch coverage, the location of the batch line is calculated. The location in this
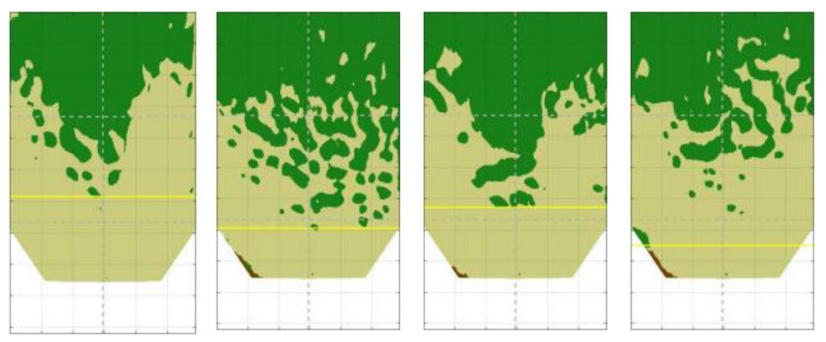

Fig. 3 Batch line recognition examples. A bright area means molten glass, green —an unmelted batch, brown — stubble on the camera 


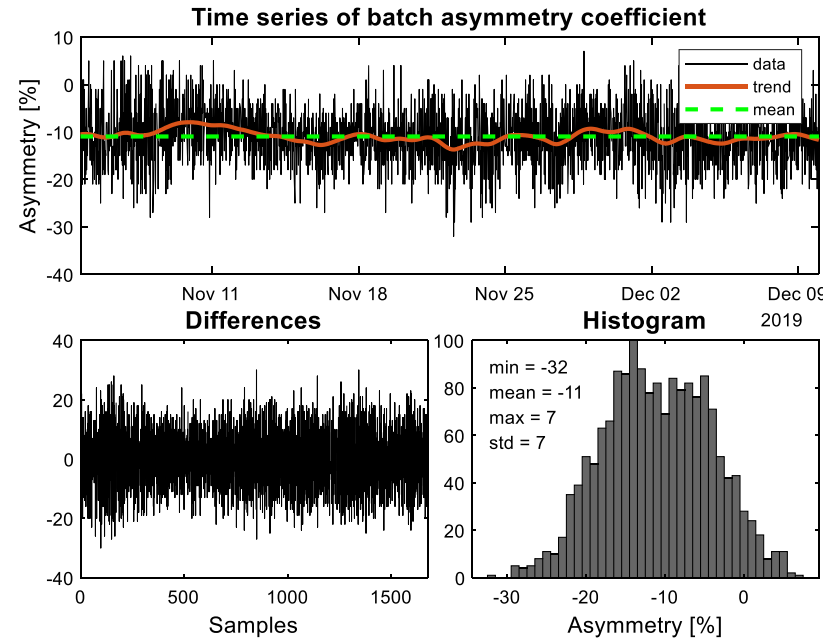

Fig. 4 Time series of the batch asymmetry along with the plot of differences and the histogram

context is the position of the farthest (from the burner wall), unmelted part of the batch (yellow line in the image of the glass pane). Figure 3 shows different examples of recognising this line. The first three examples are correct, and the last is incorrect. In practice, incorrect identification is rare. It is usually caused by misclassifying stubble on the camera as a batch. During the analysed period, incorrect line recognition occurred 47 times out of 1678 reversals, which is $2.8 \%$ of all cases.

For correct operation, the vision system needs information from the furnace control system, such as the beginning of the reversal (initiates analysis of the camera image), time to the next reversal (for information purposes) and information about which burner is currently operating (to divide the asymmetry into the left and right burner). This information is obtained from the SCADA system using the OPC protocol (for security reasons, the system is not connected directly to the PLC).

\section{Data analysis}

Data from 35 days of continuous operation of the installation (about $847 \mathrm{~h}$ ) were taken for analysis. The data cover 1678 reversals.

\subsection{Analysis of the asymmetry of the batch distribution}

Figure 4 shows time series of the asymmetry in the analysed period. Each point on the graph represents the average asymmetry of the batch calculated during one reversal. The same figure also shows the histogram and the plot of the asymmetry differences.
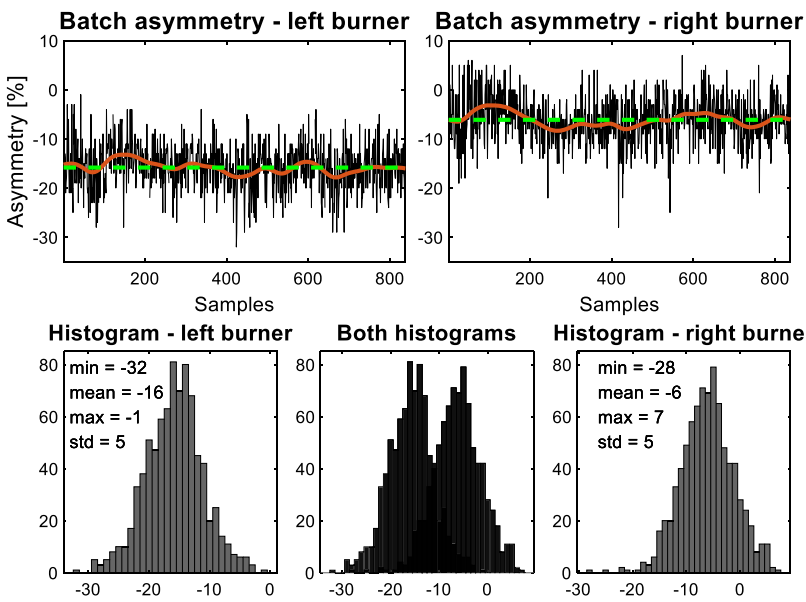

Fig. 5 Batch asymmetry depending on the working burner

The average value of the batch asymmetry is $-11 \%$ (this means that, statistically, 11 per cent more batch is on the right side of the furnace). The smallest registered asymmetry is $-32 \%$, the highest is $7 \%$, and the standard deviation is $7 \%$. Statistically, the asymmetry distribution resembles a normal distribution with a slightly outlined bimodality (see the histogram in Fig. 4). On the basis of the plot of the asymmetry differences (differences of consecutive asymmetry values), we can conclude that the asymmetry fluctuates strongly from reversal to reversal. The variance of the differences is high, reaching approx. 136.

The oscillation of the asymmetry from reversal to reversal shows that batch asymmetry depends on the burner that was operating before the reversal. In fact, when analysing the asymmetry for each burner separately, we can see interesting relationships. The asymmetry after the operation of the left burner means that we only analyse the measurements taken during the reversals directly preceded by the operation of the left burner (see the left chart in Fig. 5). The asymmetry for the reversals preceded by operation of the right burner is presented in the chart on the right.

First, there is a clear difference in the mean values of asymmetry: -16 for the left burner compared to -6 for the right burner. Both averages are negative (which means statistically more batch on the right side of the furnace), but for the right burner the absolute value is much smaller than for the left burner. This means that, after operation of the left burner, approx. $10 \%$ more of the batch is accumulated on the right side of the furnace than after the operation of the right burner. Therefore, the batch distribution after operation of the left burner has much greater asymmetry. The standard deviation for both cases is 5\%, which is approx. $29 \%$ lower than for analysis of all measurements without separation into the right and left burners. This proves that the process has a different character for the left and right burner. 

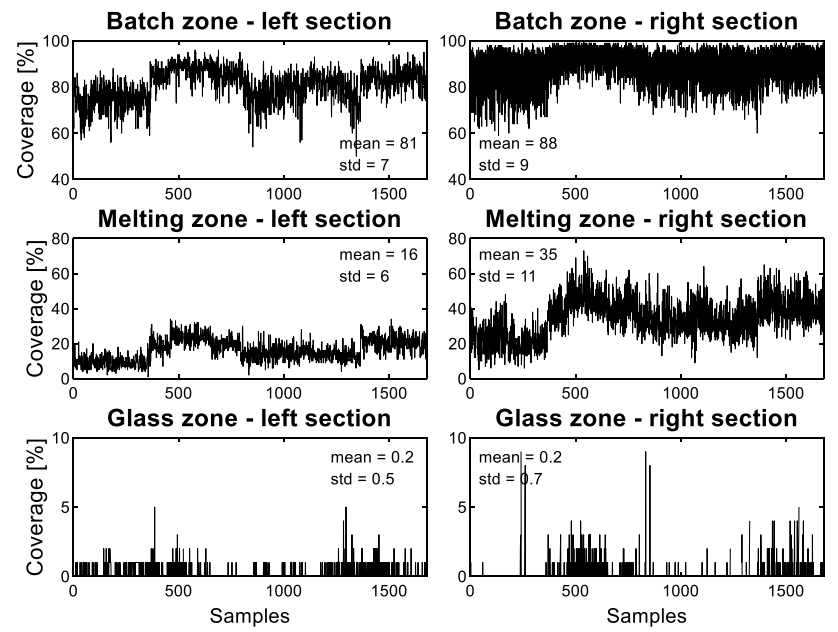

Fig. 6 Batch coverage for each zone of the furnace

Certainly, the construction of the furnace with only one batch hopper contributes to the asymmetry in the batch distribution. During the operation of the left burner (the one closest to the hopper), the batch piles pushed out of the hopper will not have time to melt and flow to the right side of the furnace, where they accumulate. The problem could most likely be solved by adapting the hopper operation depending on which burner is currently operating.

In addition to the asymmetry distribution, the degree of batch coverage of the furnace tank was also analysed. In our vision system the image of the tank has been divided into three zones (dashed lines in Fig. 2e). These are the batch zone, the melting zone and the glass zone. During each reversal, coverage percentage is calculated for the left and right size of each zone. Figure 6 shows the coverage charts of each zone for 1678 consecutive reversals. These trends reveal some interesting information:

- Oscillations are much larger for the right side of the furnace (greater deviations from the mean).

- In the batch zone, the mean coverage value for the right side is approx. $8 \%$ greater, and the standard deviation $22 \%$ greater, than for the left side.

- In the melting zone, the mean value for the right side is approx. 54\% greater, and the standard deviation $45 \%$ greater, than for the left side.

- In the glass zone, the mean value for the right side is similar, and the standard deviation is $28 \%$ larger, than for the left side.

The greatest asymmetries are in the middle of the furnace. The distribution of the batch on the left side of the furnace is more stable (less variance).

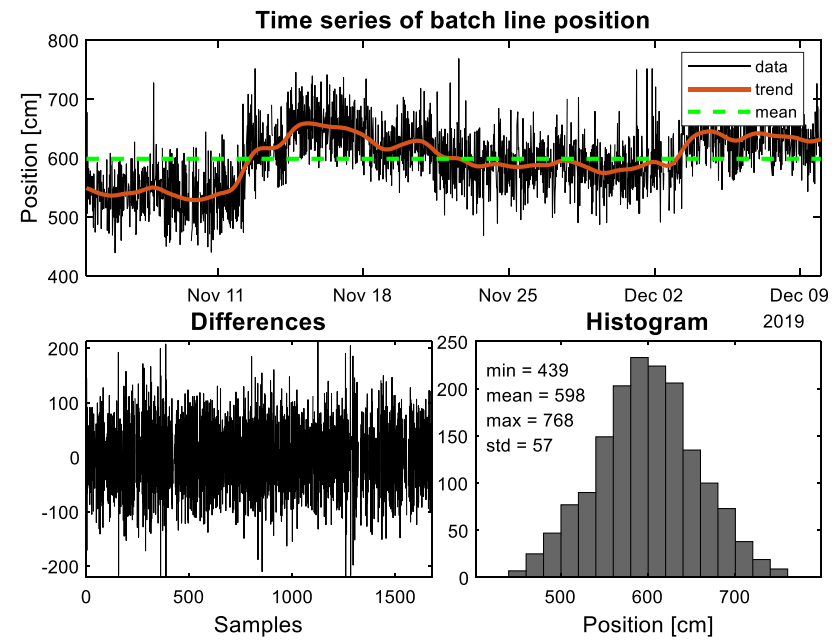

Fig. 7 Batch line position

Table 1 Statistics for raw waveforms and differences for batch line and batch asymmetry

\begin{tabular}{llllll}
\hline & \multicolumn{2}{l}{ Raw time series } & & \multicolumn{2}{l}{ Differences } \\
\cline { 2 - 3 } & std. & var. & & std. & var. \\
\hline Batch asymmetry & 0.1751 & 0.0306 & & 0.1945 & 0.0378 \\
Batch line position & 0.1743 & 0.0304 & & 0.1648 & 0.0272 \\
\hline
\end{tabular}

\subsection{Analysis of the batch line}

Time series of the batch line positions for 1678 reversals are presented in Fig. 7. The values represent the distance of the batch line from the burner wall in $\mathrm{cm}$.

Analysis of the chart shows that the position of the batch line, unlike the asymmetry coefficient, is non-stationary due to mean value. This is mainly because the batch line position largely depends on the actual furnace pull value. In Table 1 we present the statistics (standard deviation and variance) for the time series of batch line position and batch asymmetry, normalised to the range $[0,1]$. The results are shown for the raw time series and their differences. The variance of both raw time series is very similar (approx. 0.03), while in the case of differences, the asymmetry variance $(0.0378)$ is greater than the batch line position variance $(0.0272)$ by approx. $39 \%$. This means that the asymmetry is much more variable from reversal to reversal than the batch line. Unlike asymmetry, burner reversals do not have much of an effect on the batch line position.

\subsection{Analysis of the relationship between batch asymmetry and batch line and other process variables}

One of the goals of this research was to discover the relationship between the batch asymmetry, the batch line position, 
Table 2 List of process variables from scada system

\begin{tabular}{lll}
\hline Tag name & Description & Unit \\
\hline MG_FLOW_PV & Gas flow to the burners & $\mathrm{Nm}^{3} / \mathrm{h}$ \\
FU_PULL & Glass pull & $\mathrm{t} / 24 \mathrm{~h}$ \\
FU_LEV_PV & Glass level in the furnace tank & $\mathrm{mm}$ \\
BC_SPD_PV & Batch charging speed & $\%$ \\
EBM_PWR_PV & Electric boosting of melting & $\mathrm{kW}$ \\
EBB_PWR_PV & Electric boosting of barrier & $\mathrm{kW}$ \\
ME_TEMP_PV & Glass temperature & ${ }^{\circ} \mathrm{C}$ \\
\hline
\end{tabular}

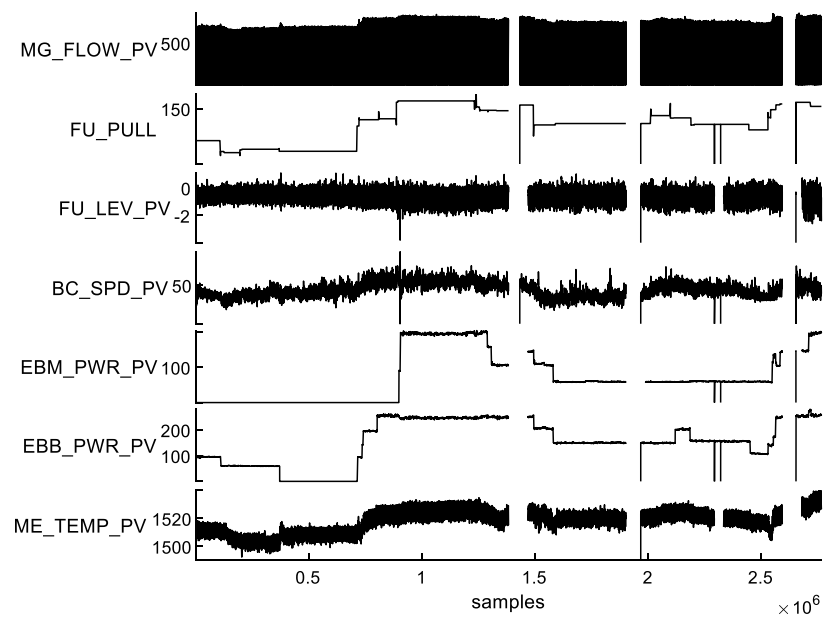

Fig. 8 Time series of the variables from the SCADA system

Table 3 Data gaps

\begin{tabular}{|c|c|c|c|}
\hline No. & From & To & Length \\
\hline 1 & 19/11/19 23:59:59 & 20/11/19 13:47:01 & $13 \mathrm{~h} 47 \mathrm{~m} 2 \mathrm{~s}$ \\
\hline 2 & 25/11/19 23:59:59 & 26/11/19 18:15:50 & $18 \mathrm{~h} 15 \mathrm{~m} 51 \mathrm{~s}$ \\
\hline 3 & $30 / 11 / 19$ 12:37:32 & $30 / 11 / 19$ 12:39:32 & $0 \mathrm{~h} 2 \mathrm{~m} 0 \mathrm{~s}$ \\
\hline 4 & $30 / 11 / 19$ 12:49:40 & $30 / 11 / 1912: 51: 33$ & $0 \mathrm{~h} 1 \mathrm{~m} 53 \mathrm{~s}$ \\
\hline 5 & 30/11/19 20:19:10 & $30 / 11 / 19$ 20:20:17 & $0 \mathrm{~h} 1 \mathrm{~m} 7 \mathrm{~s}$ \\
\hline 6 & 03/12/19 23:59:59 & 04/12/19 16:51:27 & $16 \mathrm{~h} 51 \mathrm{~m} 28 \mathrm{~s}$ \\
\hline
\end{tabular}

and other process variables that have the greatest impact on the operating parameters of the glass furnace. These other variables were logged by the SCADA production system in the glassworks. The variables, directly related to the operation of the furnace, were used for analysis, as listed in Table 2.

For the same period as for the asymmetry and batch line analysis ( 35 days of continuous operation of the installation), data were collected from SCADA (logged with a sampling period of $1 \mathrm{~s}$ ). Each variable is $2,764,801$ samples long. The time series of these variables are presented in Fig. 8.

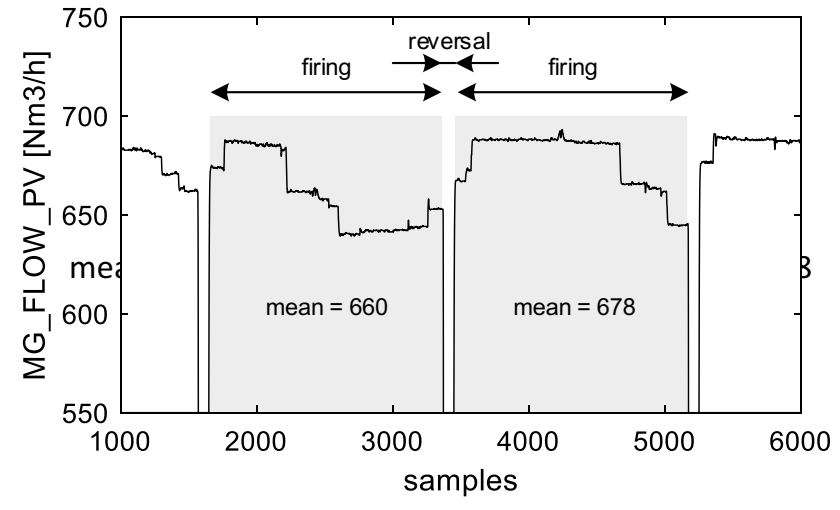

Fig. 9 Fragment of the MG_FLOW_PV variable for three consecutive reversals

As can be seen the data are not continuous. There are some gaps in the analysed period. The shortest gap is two minutes long and the longest is over $18 \mathrm{~h}$ (see Table 3 ). It is difficult to say why the SCADA system did not log data during these periods.

The batch charger parameters (like the feeder positions and the feeding hopper speed) are certainly important for the asymmetry of the batch. However, these variables remained constant throughout the observation period and were therefore not included in analysis.

Data regarding the batch distribution and position of the batch lines were collected from the vision system every $30 \mathrm{~min}$. This is due to the fact that analysis of the glass surface can only be performed during the reversal, when there is no flame in the camera's field of view. On the other hand, data from SCADA are logged every second, which causes a problem in analysis. Therefore, we divided SCADA measurements into 30-min firing fragments and 1-min reversal fragments. Each 30-min data packet was aggregated to its average value. Thanks to this, it is possible to check how the averaged values of the process variables from the firing period affect the parameters calculated in the reversal period (the asymmetry and batch line position).

For example, the plot of the MG_FLOW_PV variable (burner gas flow) shown in Fig. 8 is very densely sampled (2,764,801 samples). Therefore, its character is not clearly visible. Figure 9 shows a fragment of the plot, including three reversals. The data range between two consecutive reversals is the firing cycle (during the reversal, the gas flow drops to zero). For each cycle, the average value was calculated from 1800 samples (which corresponds to $30 \mathrm{~min}$ of firing). These values constitute a new time series of the aggregated process variable. The above procedure was applied to all analysed variables from SCADA. The charts of aggregated variables are presented in Fig. 10, where each point is the average of the 30-min firing periods. 


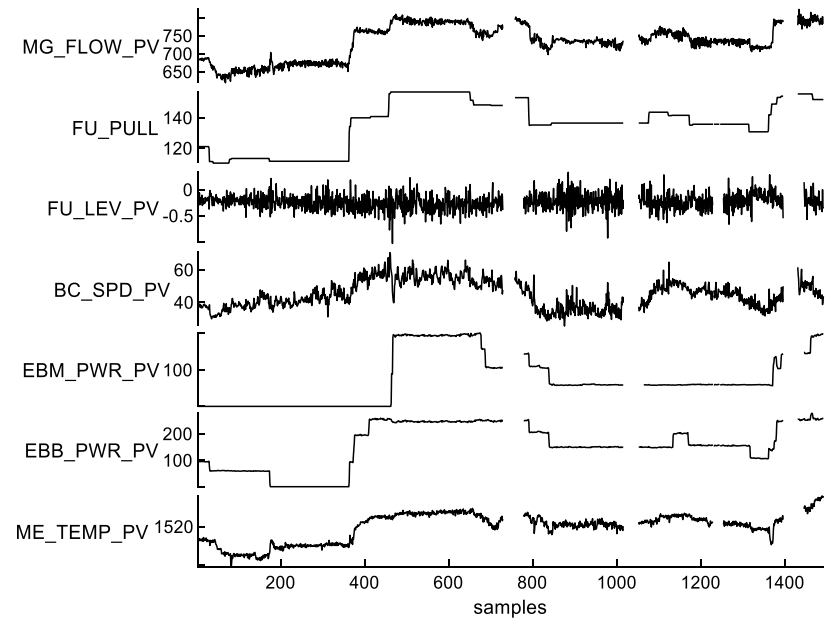

Fig. 10 Aggregated process variables from the SCADA system batch asymmetry probably depends mainly on the parameters of the batch hopper operation, which we are not able to check here due to the lack of variability of these parameters. The other parameters that we considered apparently do not affect the asymmetry value. However, we can see the potential of predicting the position of the batch line based on other variables, which will be the subject of the next section.

\section{Estimation of batch line position}

We used machine learning methods to create a number of models predicting the position of the batch line on the basis of selected process variables. The best of the several dozen tested models turned out to be the regression model, calculated using the GPR method (Gaussian Process Regression-a non-parametric kernel-based probabilistic model)

Table 4 The cross-correlation matrix

\begin{tabular}{|c|c|c|c|c|c|c|c|c|c|}
\hline & Batch line & $\begin{array}{l}\text { Batch asym- } \\
\text { metry }\end{array}$ & $\begin{array}{l}\text { MG_FLOW_ } \\
\text { PV }\end{array}$ & FU_PULL & $\begin{array}{l}\text { FU_LEV_- } \\
\text { PV }\end{array}$ & $\begin{array}{l}\text { BC_SPD_ } \\
\text { PV }\end{array}$ & $\begin{array}{l}\text { EBM_PWR_ } \\
\text { PV }\end{array}$ & $\begin{array}{l}\text { EBB_PWR_ } \\
\text { PV }\end{array}$ & $\begin{array}{l}\text { ME_TEMP_ } \\
\text { PV }\end{array}$ \\
\hline Batch line & 1 & 0.13 & 0.63 & 0.65 & -0.11 & 0.39 & 0.56 & 0.62 & 0.54 \\
\hline $\begin{array}{l}\text { Batch asym- } \\
\text { metry }\end{array}$ & 0.13 & 1 & -0.11 & -0.11 & -0.24 & 0.02 & -0.1 & -0.11 & -0.1 \\
\hline $\begin{array}{l}\text { MG_FLOW_ } \\
\text { PV }\end{array}$ & 0.63 & -0.11 & 1 & 0.97 & -0.08 & 0.61 & 0.79 & 0.91 & 0.93 \\
\hline FU_PULL & 0.65 & -0.11 & 0.97 & 1 & -0.1 & 0.59 & 0.84 & 0.94 & 0.91 \\
\hline FU_LEV_PV & -0.11 & -0.24 & -0.08 & -0.1 & 1 & -0.34 & -0.07 & -0.11 & -0.11 \\
\hline BC_SPD_PV & 0.39 & 0.02 & 0.61 & 0.59 & -0.34 & 1 & 0.46 & 0.57 & 0.52 \\
\hline $\begin{array}{l}\text { EBM_PWR_ } \\
\text { PV }\end{array}$ & 0.56 & -0.1 & 0.79 & 0.84 & -0.07 & 0.46 & 1 & 0.77 & 0.76 \\
\hline $\begin{array}{l}\text { EBB_PWR_ } \\
\text { PV }\end{array}$ & 0.62 & -0.11 & 0.91 & 0.94 & -0.11 & 0.57 & 0.77 & 1 & 0.88 \\
\hline $\begin{array}{l}\text { ME_TEMP_ } \\
\text { PV }\end{array}$ & 0.54 & -0.1 & 0.93 & 0.91 & -0.11 & 0.52 & 0.76 & 0.88 & 1 \\
\hline
\end{tabular}

To check the linear relationship between the process variables, the cross-correlation coefficients for each pair of variables were calculated (see Table 4).

From the above matrix we can conclude that:

- There is no linear correlation between the batch asymmetry and the batch line.

- There is no linear correlation between batch asymmetry and other SCADA variables.

- There is a clear linear correlation between the batch line and the other process variables, especially MG_FLOW_ PV, FU_PULL, EBB_PWR_PV.

Certainly, the fact that there is no simple linear relationship in the data does not mean that there is no more complicated non-linear relationship. The above results suggest that
Table 5 Parameters of the batch line position model

\begin{tabular}{llll}
\hline Input & Output & Type of model & Accuracy \\
\hline MG_FLOW_PV & Batch line & Exponential GPR & RMSE $=38.6$ \\
FU_PULL & & & $\mathrm{R}^{2}=0.56$ \\
BC_SPD_PV & & Neural Net & RMSE $=31.3$ \\
EBM_PWR_PV & & & $\mathrm{R}^{2}=0.84$ \\
EBB_PWR_PV & & & \\
ME_TEMP_PV & & & \\
\hline
\end{tabular}

[18]. The input variables are listed in Table 5.

The mean square error of the model fit to the actual data (calculated using the five-fold cross-validation method) is 38.6 (RMSE), and the fit factor $\mathrm{R}^{2}$ is 0.56 . These results show that the model is not very accurate. 


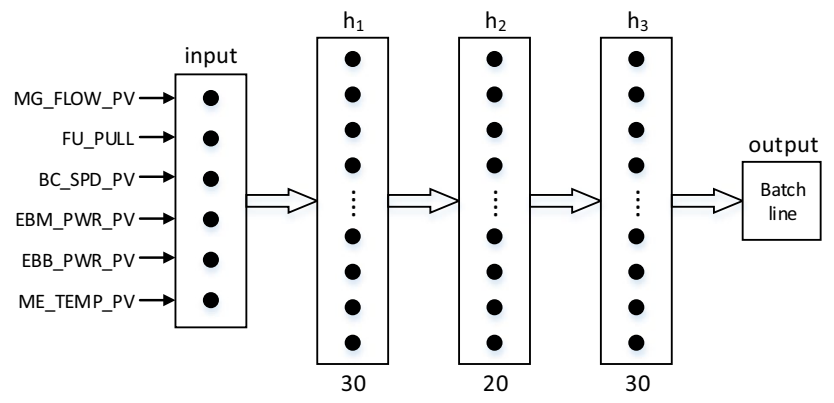

Fig. 11 Neural network with three hidden layers. Big blank arrows indicate fully connected layers
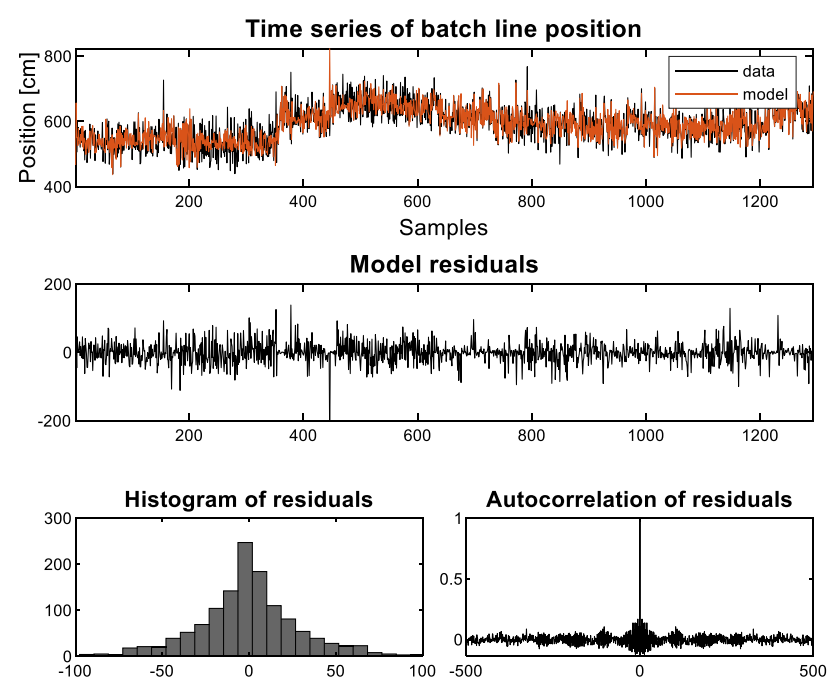

Fig. 12 Results of modelling the batch line position using a neural network

Since the classical methods did not give satisfactory results, we used artificial neural networks. We arbitrarily assumed a shallow network with three hidden layers (see Fig. 11). The inputs and outputs were the same as for the regression model. The data were randomly divided into a training set $(70 \%)$, used to train the network, a validation set (15\%), used to assess the effectiveness of the learning process, and a test set (15\%), on which the final accuracy of the model was verified.

Since the learning method and the number of neurons in individual hidden layers are hyperparameters that cannot be determined optimally in advance, a simple method was used to search the space of parameters. For each of 11 back propagation-based learning methods (such as BFGS quasi-Newton, Conjugate gradient, Gradient descent with adaptive learning rate, Gradient descent with momentum, Levenberg-Marquardt, and Bayesian regularisation), all combinations of architectures with three hidden layers, where the number of neurons in each layer varied from 10 to 50 with a step of 10 , were created and trained. As a result, 1375 networks were obtained, the best of which was the network size $[\mathrm{h} 1=30, \mathrm{~h} 2=20, \mathrm{~h} 3=30]$ and the learning method based on back-propagation with Bayesian regularisation [19].

When analysing the results shown in Fig. 12, it can be seen that the model follows the trend in the data, although it does not reflect all the details. The histogram of the model residuals (the differences between the model and the actual data) and the auto-correlation waveform of the residuals indicates that the residuals are practically uncorrelated white noise. This means that the residuals do not contain any useful information, so the model is adequate. The mean square error of fitting the model output to the real data is 31.3 , and the fit coefficient $R^{2}$ is 0.84 . The results are much better than for the regression model. Such a model could be used to predict the position of the batch line depending on other process variables in the glass furnace.

\section{Conclusion}

The information obtained from our vision system allowed observation of phenomena occurring in glass furnaces, which were previously difficult to notice. Historical data on batch asymmetry show that the furnace distributes the batch asymmetrically-10\% more batch is accumulated on the right side of the furnace. Moreover, data analysis showed that the asymmetry was greatly influenced by which burner was running before the reversal, and that asymmetry was much greater after operation of the left burner. The large asymmetry of the batch in the furnace is disadvantageous, as it makes it difficult to melt the batch evenly and may lead to the penetration of the unmelted batch into the working end.

Historical data of the batch line position allows an assessment of whether the operator is controlling the process optimally. Typically, operators tend to shorten the batch line unnecessarily to avoid the risk of unmelted glass entering the working end. However, doing so leads to much higher energy consumption and process inefficiency.

Summarising this research, it can be stated that:

- On the basis of the available data, it is not possible to find a relationship between the asymmetry of the batch and other process variables. Perhaps carrying out some experiments on the object, such as changing the batch charger parameters in a carefully planned scenario, would provide new data useful for this analysis.

- The location of the batch line can be estimated based on aggregated SCADA data. We have tested several models and the best accuracy was achieved using the model based on neural network. Revealing a complex relationship between process parameters and batch line position 
can be used for optimisation of the furnace operation, which is currently based on the experience of human operators.

In future research, additional process variables logged in SCADA can be included in analysis. These variables may include gas calorific value or the level of a glass cullet in the batch (as it acts as a fluxing agent and decreases the melting energy). Perhaps it would make sense to build a separate model for each burner, because, as research has shown, the process is slightly different depending on which burner is working.

From the point of view of the process operator, running the process as efficiently as possible is important. Therefore, operators should observe the following recommendations:

- The operator should control the batch asymmetry trend and properly adjust the batch charger settings and the load of both burners so that the asymmetry coefficient is as close as possible to zero.

- The operator should also control the trend of the line position of the batch and adjust the amount of energy supplied to the furnace appropriately, to ensure optimal line position. Too short a line increases energy consumption, and too long a line may result in the penetration of unmelted glass into the working end.

Acknowledgements This research is a result of cooperation between AGH University of Science and Technology and Techglass Ltd. We would like to thank the employees of Techglass Ltd. and Zignago Vetro Polska S.A. for their cooperation and many helpful comments.

Authors contributions PR conceived this research and designed algorithms for vision analysis. MK designed the vision system, implemented it in the glassworks, and conducted data analysis. AS directed the research in the context of glass production and provided the data.

Funding This work was supported in part by the Polish Ministry of Science and Higher Education from research subsidy 16.16.120.773.

Availability of data and materials The authors do not provide data and additional materials.

\section{Declarations}

Conflict of interests The authors declare no competing interests.

Consent to publish The authors consent to the publication of this article in Production Engineering-Research and Development.

Open Access This article is licensed under a Creative Commons Attribution 4.0 International License, which permits use, sharing, adaptation, distribution and reproduction in any medium or format, as long as you give appropriate credit to the original author(s) and the source, provide a link to the Creative Commons licence, and indicate if changes were made. The images or other third party material in this article are included in the article's Creative Commons licence, unless indicated otherwise in a credit line to the material. If material is not included in the article's Creative Commons licence and your intended use is not permitted by statutory regulation or exceeds the permitted use, you will need to obtain permission directly from the copyright holder. To view a copy of this licence, visit http://creativecommons.org/licenses/by/4.0/.

\section{References}

1. Kawaguchi M, Kato T, Imamura Y, Yoshida N, Aoki S (2008) Challenge to improve glass melting and fining process. In: presented at the Advanced Glass Materials and Innovative Glass Melting Technology in the Year 2020, Brig, Switzerland

2. Ross CP, Tincher GL (2004) Glass melting technology: a technical and economic assessment. In: Glass Manufacturing Industry Council, US Department of Energy Industrial Technologies Program

3. Rotter P, Skowiniak A (2013) Image-based analysis of the symmetry of the glass melting process. Glass TechnolEur J Glass SciTechnol Part A 54:119-131

4. Rotter P (2014) Extraction of relevant glass melting parameters based on the pairwise comparisons of sample images from a furnace. Glass TechnolEur J Glass SciTechnol Part A 55:55-62

5. Grega W, Tutaj A, Klemiato M, Byrski W (2016) Comparison of real-time industrial process control solutions: glass melting case study. In: MMAR 2016: 21th international conference on Methods and Models in Automation and Robotics, Międzyzdroje, Poland

6. Rotter P, Klemiato M (2017) Prototype vision-based system for the supervision of the glass melting process: implementation for industrial environment. In: Advances in intelligent systems and computing, Springer International Publishing, cop. 2017. ISSN 2194-5357; vol. 577, ISBN: 978-3-319-60698-9

7. Laizola E, Jimenez AR, Morgado F, Calvache M, Seco F (2003) Computer-vision-based gob inspection system for monitoring and control in glass industry. Mach Vis ApplInd Inspection XI SPIE 5011:90-100

8. Garbacz P (2019) Inspection of tableware glass products at the hot end of production line. J Mach Constr Maintenance 112:77-84

9. Hotar V (2008) Monitoring of glass production using vision systems. Adv Mater Res 39-40:511-516

10. Nishu A, Agrawal S (2011) Glass defect detection techniques using digital image processing - a review, special issues on IP. Multimedia Commun 1:65-67

11. Garbacz P, Giesko T, Czajka P, Mazurkiewicz (2017) Vision system for inspection of glass furnace structure. In: presented at the International Conference Automation (ICA)

12. Santos-Victor JA, Costeira JP, Tome JAB, Sentieiro JJS (2002) A computer vision system for the characterization and classification of flames in glass furnaces. IEEE Trans IndAppl 29(3):470-478

13. Muller J, Chmelar J, Bodi R, Matustik F, Viktorin P (2013) Automatic batch position control by expert system ESIIITM. In: presented at the 23rd International Congress on Glass (ICG), Prague

14. Czajka P, Mizak W (2019) A method for monitoring glass melt surface in a glass furnace. J Mach Constr Maintenance 4:37-48

15. Rotter $P$ (2017) Virtual cameras and stereoscopic imaging for the supervision of industrial processes. In: Artificial Intelligence and Soft Computing, Proceedings of the 16th International Conference on Artificial Intelligence and Soft Computing, ICAISC 2017, Zakopane, pp 563-659

16 Hartley R, Zisserman A (2003) Multiple view geometry in computer vision. Cambridge University Press, Cambridge

17. Ross CP (2004) Innovative glass melting technologies. Am Ceram Soc Bull 83(1):18-20 
18. Rasmussen CE, Williams CKI (2006) Gaussian processes for machine learning. MIT Press, Cambridge

19. Schagen J, Beerkens R, Faber A, Hemmann P, Hemmann G (2008) Application of batch blanket monitoring system in glass furnaces. In: 64th conference on glass problems: ceramic engineering and science proceedings, volume 25 , pp 209-218
Publisher's Note Springer Nature remains neutral with regard to jurisdictional claims in published maps and institutional affiliations. 